\title{
ASSESSMENT OF EARLY RETINAL ANATOMICAL AND FUNCTIONAL CHANGES IN HYDROXYCHLOROQUINE TREATED PATIENTS BY MULTIFOCAL ELECTRORETINOGRAM AND OPTICAL COHERENCE TOMOGRAPHY
}

By

\section{El-Sayed Mostafa Eliwa, Mostafa Mahmoud Mostafa and Ahmed Ragab Awad Omar}

Departments of Ophthalmology, Faculty of Medicine, Al-Azhar University

Corresponding author: Ahmed Ragab Awad Omar,

E-Mail: ahmedomardr@gmail.com, Mobile: 01114566044

\begin{abstract}
Background: Patients having treated with hydroxychloroquine (HCQ) can have retinal function and morphological changes with no evident retinal abnormalities on ophthalmoscopy this can be detected by various imaging Tanique's.

Objective: We aimed to evaluate the early changes of retinal function by multifocal electroretinogram (MFERG) and morphology by spectral domain optical coherence tomography (SD-OCT) that may eventually occur in a population of subjects having Rheumatoid Arthritis treated with hydroxychloroquine with no evident retinal abnormalities on ophthalmoscopy.

Patients and methods: A prospective study on 30 eyes of patients treated with HCQ (Patient group) and another 30 healthy eyes (control group). SD-OCT and MF-ERG was done in both groups. All patients underwent full medical and ophthalmic history including onset and duration of disease and HCQ therapy, history of ocular surgeries. All patients underwent complete ophthalmic examination including visual acuity: uncorrected VA (UCVA) and best corrected VA (BCVA), anterior segment examination using slit-lamp biomicroscopy, intraocular pressure (IOP) measurement by applanation tonometry, fundus examination, OCT imaging using SD-OCT, and MF-ERG imaging.

Results: In patients treated with HCQ, there was a significant reduction in the pri-foveal macular thickness by SD-OCT in comparison to control group. There were also significant MF-ERG changes in the form on decreased P1-wave amplitude and increased P1-wave latency.

Conclusion: MF-ERG and SD-OCT were very sensitive tests for the early detection of HCQ-related retinal toxicity. Using either MF-ERG or SD-OCT, or combination of them may be recommended in order to detect retinal changes earlier and also in follow up.
\end{abstract}

Keywords: Hydroxychloroquine Retinopathy, Multifocal Electroretinogram, Spectral Domain Optical Coherence Tomography, Chloroquine toxicity. 


\section{INTRODUCTION}

Retinopathy is the most important ophthalmologic complication of antimalarial therapy. Antimalarials bind to melanin in the pigmented epithelial layer of the retina, an effect that may damage rods and cones and lead to permanent vision loss. The exact incidence of retinopathy is uncertain. With at least 10 years of use it may occur in up to 3 to 4 percent of patients taking HCQ, up to 10 percent taking CQ. (Melles and Marmor, 2014).

Fundus examination alone is incapable of predicting future drug-induced retinopathy. Many functional and imaging exams have been proposed for the early detection of retinal damage (Lyons and Severns, 2009).

To detect hydroxychloroquine toxicity, the American Academy of Ophthalmology recommends, in addition to fundus examination, objective tests like: multifocal electroretinography or spectral domain optical coherence tomography (Marmor et al., 2011).

Optical coherence tomography (OCT) is a noninvasive method that evaluates biological tissues by in vivo imaging. Since its introduction, OCT has undergone several improvements and revolutionized the diagnostic, monitoring, and therapeutic approaches to many retinal diseases. Computerized algorithms can be used on the high-resolution images obtained by modern OCT devices to identify and measure the thicknesses of discrete retinal layers, including the retinal nerve fiber layer (RNFL), macular ganglion cell complex (GCC), and choroid. (Shao et al., 2013).
Multifocal electroretinogram was developed by Sutter and Tran in 1992 for recording responses from many regions of the retina. This objective measurement was introduced because full field flash electroretinography records mass responses from the whole retina. The multifocal ERG (mf-ERG) derives simultaneously a local photopic ERG at each of a number of locations in the central visual field. This allows a topographic determination of ERG function within the central radius of 25 to 30 degrees of the fundus. The summed potentials of the conventional flash ERG, by contrast, do not permit a localization of retinal disease (Lung et al., 2012).

\section{PATIENTS AND METHODS}

This study was conducted in Ophthalmology Department at Al Hussein University Hospital, Faculty of Medicine, Al-Azhar University.

This study was approved by the Ethics Board of Al-Azhar University.

This was a Comparative prospective study that included 30 eyes of 15 patients having Rheumatoid Arthritis taking HCQ and another 30 eyes of 15 healthy control subjects.

Patients were recruited from the rheumatology clinic of Al-Azhar University Hospitals in the period from December, 2018 to September, 2019. MFERG and SD-OCT was done at Al-Azhar University Hospitals. Approval for the study was obtained from the hospital's ethical committee. All patients received a thorough explanation of the study design and aims, and gave written informed consents. All participants confirmed their ability to follow study instructions. 


\section{Inclusion criteria:}

A fundus without significant alterations of the macula and retina, age between $20-70$ years old of either gender, subject cooperation sufficient for adequate fundus photographs, and longterm use of hydroxychloroquine (more than one-year duration).

\section{Exclusion criteria:}

Patients with media opacity that prevent adequate OCT such as dense cataract, patients with glaucoma, with history of photocoagulation, who had refractive errors greater than 6 diopters, astigmatism greater than 3 diopters, patients with visual acuity below $6 / 60$, patients with diabetic retinopathy, agerelated macular degeneration(AMD) and, patients with any form of tropia or phoria.

Intervention and outcome measures: After meeting all inclusion criteria, the patients were evaluated by full medical/ophthalmic history including onset of RA and duration of HCQ therapy, and complete ophthalmic examination including best corrected visual acuity, slit lamp examination to the anterior segment, detailed fundus examination by slit lamp biomicroscopy, and measurement of IOP using Goldmann's applanation tonometer .

Spectral domain optical coherence tomography (SD-OCT) was done to all eyes using the Optovue RTVue model RT100, Optovue, Inc., Fremont, CA. The used scans are; Electronic Macular Map 5 $\mathrm{mm}$ (EMM5) is $5 \times 5 \mathrm{~mm}$ square grid centered on fixation. The grid spacing is $0.25 \mathrm{~mm}$ in the inner $3 \times 3 \mathrm{~mm}$ area and 0.5 $\mathrm{mm}$ in the outer area, the map of macular thickness was composed of three concentric circles: a central circle (fovea), an inner circle (parafovea), and an outer circle (perifovea) with radii of $1 \mathrm{~mm}, 3$ $\mathrm{mm}$, and $5 \mathrm{~mm}$, respectively.

\section{Multi-Focal Electroretinogram}

Mf-ERG was done on Roland Consult RETI-port gamma plus 2 with the following technique: After pupillary dilation with $1 \%$ tropicamide eye drops and corneal topical anesthesia with $0.4 \%$ oxybuprocaine hydrochloride eye drops, ERG HK-Loop electrodes were applied on the inferior conjunctival fornix with ground and reference electrodes positioned on forehead and temporal regions. Electrical impedance was less than $5 \mathrm{kOhm}$ for all electrodes. mfERG was recorded monocularly using a 61hexagon stimulus according to International Society for the Clinical Electrophysiology of Vision guidelines, with 21 inches video stimulating display (CRT monitor, $75 \mathrm{~Hz}$ frame rate, cut-offs $10-100 \mathrm{~Hz}$ ), subtending $30^{\circ}$ on either side of fixation. The room light was on during stimulation and the screen-patient distance was $28 \mathrm{~cm}$. The radius of the central hexagon was $2^{\circ}$ and a red central-fixation cross $2 \mathrm{~mm}$ in diameter was used. During stimulation, each element was either black or white $(93 \%$ contrast $)$ and mean luminance was $51.8 \mathrm{~cd} / \mathrm{m} 2$.

Mean responses, as assessed by the analysis of five concentric stimulus rings, were passed through a band-pass filter set to $10-300 \mathrm{~Hz}$. The standard measurement for amplitude was the trough-to-peak amplitude measured from the trough of N1-wave to the peak of P1-wave and was expressed in nv, while the standard measurement for timing was the implicit time of P1-wave peak and was expressed in $\mathrm{ms}$. 
Statistical analysis:

Data were analyzed using Statistical package for Social Science (SPSS) version 15.0. Quantitative data were expressed as mean \pm standard deviation (SD). Qualitative data were expressed as frequency and percentage.

The following tests were done: Independent-samples t-test of significance: was used when comparing between two means, Chi-square test was used when comparing between nonparametric data, and Mann-whitney U test was used when comparing when comparing between two means with abnormal distributed data.

P-value $<0.05$ was considered significant.

\section{RESULTS}

In our study patients group were 2 males and 13 females with mean age of 47.6 years there was no statistical significant difference ( $p$-value $>0.05$ ) between studied groups as regard demographic data (Table 1).

Table (1): Comparison between studied groups as regard demographic data

\begin{tabular}{|c|c|c|c|c|c|c|}
\hline \multicolumn{2}{|c|}{ Variables $\quad$ Groups } & \multicolumn{2}{|c|}{$\begin{array}{l}\text { Control } \\
(\mathbf{N}=15)\end{array}$} & \multicolumn{2}{|c|}{$\begin{array}{l}\text { Patients } \\
(\mathrm{N}=15)\end{array}$} & P-value \\
\hline \multirow{2}{*}{ Age (years) } & Mean & \multicolumn{2}{|c|}{48.4} & \multicolumn{2}{|c|}{47.6} & \multirow{2}{*}{0.81} \\
\hline & \pm SD & & & & 9 & \\
\hline \multirow{2}{*}{ Gender } & Male & 3 & $20 \%$ & 2 & $13.3 \%$ & \multirow[t]{2}{*}{0.624} \\
\hline & Female & 12 & $80 \%$ & 13 & $86.6 \%$ & \\
\hline
\end{tabular}

The mean disease and treatment duration of patients were 8.3 and 5.6 years respectively. They also received mean

cumulative HCQ dose of 632.15 grams (Table 2).

Table (2): Clinical data among 15 RA patients taking HCQ (400mg daily)

\begin{tabular}{|c|c|c|}
\hline Variables & Range & Mean \pm SD \\
\hline Disease Duration (years) & $3-14$ & $8.3 \pm 3.4$ \\
\hline Treatment with HCQ duration (years) & $2-13$ & $5.6 \pm 2.96$ \\
\hline Cumulative HCQ dose (gm.) & $412-1812$ & $632.15 \pm 513.2$ \\
\hline
\end{tabular}

All patients were asymptomatic on presentation. Anterior segment and fundoscopy were normal in all subjects. Best corrected visual acuity was $6 / 6$ in 22 eyes, 6/9 in 4 eyes and 6/12 in 4 eyes using Snellen chart and intraocular pressure ranged from 12 to $18 \mathrm{mmHg}$ by applanation tonometer. There was a statistically significant difference between studied groups as regard Peri-Foveal Macular thickness (Table 3). 
ASSESSMENT OF EARLY RETINAL ANATOMICAL AND FUNCTIONAL...

Table (3): Comparison between studied groups as regard retinal thickness of each macular area

\begin{tabular}{|c|c|c|c|c|c|}
\hline \multicolumn{3}{|c|}{$\begin{array}{ll}\text { Variables } & \text { Groups } \\
\end{array}$} & $\begin{array}{l}\text { Control } \\
(\mathrm{N}=15)\end{array}$ & $\begin{array}{l}\text { Patients } \\
(\mathrm{N}=15)\end{array}$ & P-value \\
\hline \multirow{6}{*}{ 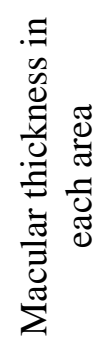 } & \multirow{2}{*}{ Foveal } & Mean & 266.1 & 264.5 & \multirow[t]{2}{*}{0.853} \\
\hline & & $\pm \mathrm{SD}$ & 22.6 & 24.3 & \\
\hline & \multirow{2}{*}{ Para-Foveal } & Mean & 324.7 & 315.1 & \multirow[t]{2}{*}{0.138} \\
\hline & & $\pm \mathrm{SD}$ & 15.4 & 18.9 & \\
\hline & \multirow{2}{*}{ Peri-Foveal } & Mean & 306.7 & 294.5 & \multirow[t]{2}{*}{0.014} \\
\hline & & $\pm \mathrm{SD}$ & 13.2 & 12.3 & \\
\hline
\end{tabular}

Further analysis of the Pri-Foveal regions of the four quadrants and comparison of the results with the control group revealed statistically significant difference between studied groups as regard Peri-Foveal retinal thickness in the superior, nasal and inferior quadrants (Table 4).

Table (4): Comparison between studied groups as regard Peri-Foveal retinal thickness

\begin{tabular}{|c|c|c|c|c|c|}
\hline \multicolumn{3}{|c|}{ Variables $\quad$ Groups } & $\begin{array}{l}\text { Control } \\
(\mathrm{N}=15)\end{array}$ & $\begin{array}{l}\text { Patients } \\
(\mathrm{N}=15)\end{array}$ & P-value \\
\hline \multirow{8}{*}{ 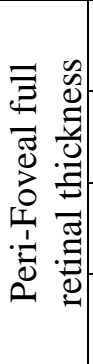 } & \multirow{2}{*}{ Temporal } & Mean & 292.7 & 286.7 & \multirow[t]{2}{*}{0.250} \\
\hline & & $\pm \mathrm{SD}$ & 13.8 & 14.2 & \\
\hline & \multirow{2}{*}{ Superior } & Mean & 296.3 & 284.8 & \multirow[t]{2}{*}{0.016} \\
\hline & & $\pm \mathrm{SD}$ & 11.5 & 13.2 & \\
\hline & \multirow{2}{*}{ Nasal } & Mean & 325.1 & 313.6 & \multirow[t]{2}{*}{0.004} \\
\hline & & $\pm \mathrm{SD}$ & 11.2 & 9.1 & \\
\hline & \multirow{2}{*}{ Inferior } & Mean & 310.9 & 303.1 & \multirow[t]{2}{*}{0.039} \\
\hline & & $\pm \mathrm{SD}$ & 9.7 & 10.1 & \\
\hline
\end{tabular}

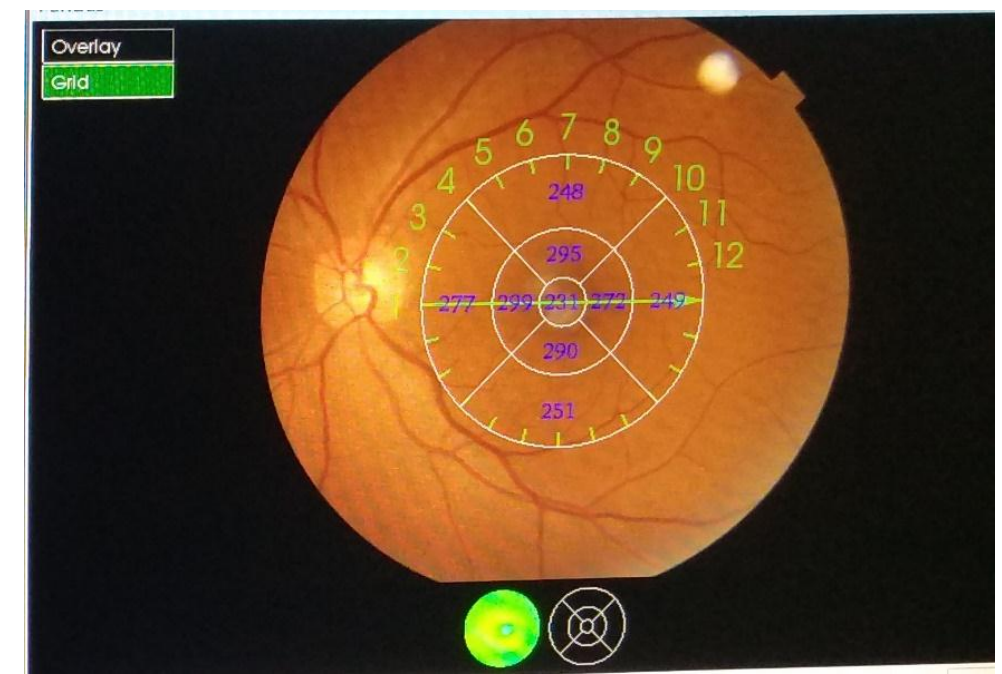

Figure (1): Oct image showing a map of the thickness of the macula. 
As regard P1-wave amplitudes there was statistically significant difference between studied groups as regard P1-wave amplitude.

Table (5): Comparison between studied groups as regard P1-wave amplitudes $\mu \mathrm{v}$

\begin{tabular}{|c|c|c|c|c|c|}
\hline \multicolumn{3}{|c|}{ Variables $\quad$ Groups } & $\begin{array}{l}\text { Control } \\
(\mathrm{N}=15)\end{array}$ & $\begin{array}{l}\text { Patients } \\
(\mathrm{N}=15)\end{array}$ & P-value \\
\hline \multirow{10}{*}{ 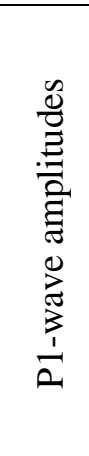 } & \multirow{2}{*}{ Ring 1} & Mean & 2.1 & 2.2 & \multirow{2}{*}{0.718} \\
\hline & & $\pm \mathrm{SD}$ & 0.8 & 0.7 & \\
\hline & \multirow{2}{*}{ Ring 2} & Mean & 1.4 & 1.1 & \multirow{2}{*}{0.039} \\
\hline & & $\pm \mathrm{SD}$ & 0.5 & 0.2 & \\
\hline & \multirow{2}{*}{ Ring 3} & Mean & 0.94 & 0.93 & \multirow{2}{*}{0.863} \\
\hline & & $\pm \mathrm{SD}$ & 0.1 & 0.2 & \\
\hline & \multirow[b]{2}{*}{ Ring 4} & Mean & 0.83 & 0.82 & \multirow{2}{*}{0.892} \\
\hline & & $\pm \mathrm{SD}$ & 0.2 & 0.1 & \\
\hline & \multirow{2}{*}{ Ring 5} & Mean & 0.93 & 0.92 & \multirow{2}{*}{0.915} \\
\hline & & $\pm \mathrm{SD}$ & 0.3 & 0.2 & \\
\hline
\end{tabular}

As regard P1-wave latencies in $\mathrm{ms}$, statistically significant difference between studied groups as regard P1-wave latencies in all rings (Table 6).

Table (6): Comparison between studied groups as regard P1-wave latencies in ms

\begin{tabular}{|c|c|c|c|c|c|}
\hline \multicolumn{3}{|c|}{ Variables $\quad$ Groups } & $\begin{array}{l}\text { Control } \\
(\mathrm{N}=15)\end{array}$ & $\begin{array}{l}\text { Patients } \\
(\mathrm{N}=15)\end{array}$ & $\mathrm{P}$-value \\
\hline \multirow{10}{*}{ 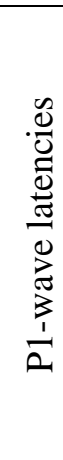 } & \multirow{2}{*}{ Ring 1} & Mean & 39.9 & 41.1 & \multirow{2}{*}{0.041} \\
\hline & & $\pm \mathrm{SD}$ & 4.7 & 4.2 & \\
\hline & \multirow{2}{*}{ Ring 2} & Mean & 36.1 & 39.4 & \multirow{2}{*}{0.019} \\
\hline & & $\pm \mathrm{SD}$ & 2.4 & 3.7 & \\
\hline & \multirow{2}{*}{ Ring 3} & Mean & 34.6 & 33.9 & \multirow{2}{*}{0.041} \\
\hline & & $\pm \mathrm{SD}$ & 1.4 & 1.6 & \\
\hline & \multirow{2}{*}{ Ring 4} & Mean & 34.9 & 34.3 & \multirow{2}{*}{0.041} \\
\hline & & $\pm \mathrm{SD}$ & 1.3 & 1.4 & \\
\hline & \multirow{2}{*}{ Ring 5} & Mean & 35.7 & 35.3 & \multirow{2}{*}{0.041} \\
\hline & & $\pm \mathrm{SD}$ & 1.5 & 1.4 & \\
\hline
\end{tabular}

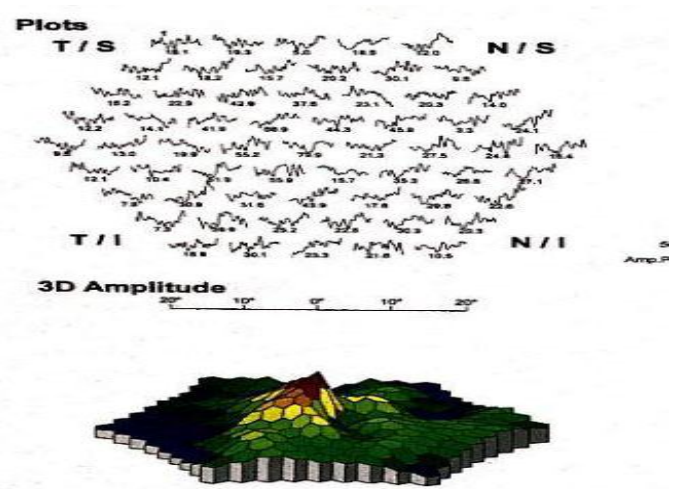

Figure (2): mfERG response in plots and 3D amplitude 


\section{DISCUSSION}

Retinopathy is the most important ophthalmologic complication of antimalarial therapy. Antimalarial bind to melanin in the pigmented epithelial layer of the retina, an effect that may damage rods and cones and lead to permanent vision loss. The exact incidence of retinopathy is uncertain; with at least 10 years of use it may occur in up to 3 to 4 percent of patients taking HCQ, up to 10 percent taking CQ (Melles and Marmor, 2014).

There's no firm definition of early toxicity and no established criteria for diagnosing HCQ toxicity before a stage where some minor permanent visual loss is likely. (Marmor et al., 2011)

Marmor and Associates (2011) have reported revised recommendation on screening for HCQ retinopathy. According to these recommendations annual screening should begin after five years or sooner, if there are unusual risk factors VF should be supplemented with sensitive objective test, such as multifocal electroretinogram (MF-ERG), SD-OCT, and fundus autofluorescence. However, relative sensitivity and specificity of these tests has not been established yet.

SD-OCT imaging and mf-ERG exhibited abnormalities in areas that appeared unaffected on VF 10-2 and clinical fundoscopic examination (Stepien et al., 2009).

In our study, we aimed to evaluate the early changes in the retina caused by the use of HCQ, morphologically by (SDOCT) and functionally by (MF-ERG) by comparing the results of two groups, 30 eyes of 15 (patients) all had RA with no visual complaints and normal fundus and 30 eyes of 15 healthy (control) group.

We found that there was a statistically significant difference as regard macular thickness in the peri-foveal region between the two groups in the form of decreased macular thickness with mean thickness of $294.5 \mu \mathrm{m}$ in patients group and mean thickness of $306.7 \mu \mathrm{m}$ in Control group.

Ulviye et al. (2013) agreed with our study as there was a significant decreased full macular thickness in the peri-foveal region in comparison to a control group, but the difference in their study was that they further analyzed the macular thickness in the inner and outer macular areas and they found a very significant reduction in the Para-Foveal macular area thickness in the Inner macular layers.

In another study, designed to compare patients with established retinal toxicity and others without toxicity, selective thinning of the inner retina was detected in the absence of clinically apparent fundus changes, but significant thinning of the inner, outer, and full thickness retina was observed in patients with retinal toxicity (Pasadhika and Fishman, 2010).

In our study, we further assessed the perifoveal and parafoveal areas in quadrants to identify which areas of the macula were more selectively affected in this early period. Measurements of the superior, inferior and nasal quadrants in the perifoveal areas significantly reduced in HCQ treated patients, but no significant difference between the two groups as regard Para-Foveal Full Macular thickness in the 4 quadrants. Ulviye et al. (2013) reported that the inner retinal thickness of the inferior quadrant of the Para-Foveal 
region had the most significant reduction in thickness.

As regard functional assessment of the retina we compared the same 15 patients MF-ERG results to the control group to compare P1 amplitude and latency.

Based on mfERG analysis, our study showed that the most frequent finding in patients treated with HCQ was P1-wave amplitude reduction in ring 2 , followed by amplitude reduction in rings 3, 4, and 1 . Regarding P1-wave latency, there was an increase in ring 2 followed by an increase in ring 1, 3, 4, and 5. These data are consistent with Moschos et al. (2015).

All patients beginning long-term HCQ therapy should have a baseline ophthalmologic examination within the first year of starting the drug to document any ocular complication and to establish a record of the fundus appearance and functional status (Marmor et al., 2011).

There are not yet sufficient data to determine when patients who showed early loss of retinal function on mfERG tests experienced significant visual impairment. It has been suggested that early discontinuation may prevent and possibly reverse damage (Korah and Kuriakose, 2008).

\section{CONCLUSION}

MF-ERG and SD-OCT are very sensitive tests for the early detection of HCQ-related retinal toxicity. Using either MF-ERG or SD-OCT, or combination of them may be recommended in order to detect retinal changes earlier and also for follow up.

\section{REFERENCES}

1. Korah, S., and Kuriakose, T. (2008): Optical coherence tomography in a patient with chloroquine-induced maculopathy. Indian journal of ophthalmology, 56(6), 511.

2. Lung, J. C., Swann, P. G., and Chan, H. H. (2012): Early local functional changes in the human diabetic retina: a global flash multifocal electroretinogram study. Graefe's archive for clinical and experimental ophthalmology, 250(12): 1745-1754.

3. Lyons, J. S., and Severns, M. L. (2009): Using multifocal ERG ring ratios to detect and follow Plaquenil retinal toxicity: a review. Documenta ophthalmologica, 118(1): 29-36.

4. Marmor, M. F., Kellner, U., Lai, T. Y., Lyons, J. S., and Mieler, W. F. (2011): Revised recommendations on screening for chloroquine and hydroxychloroquine retinopathy. Ophthalmology, 118(2): 415422.

5. Melles, R. B., and Marmor, M. F. (2014): The risk of toxic retinopathy in patients on long-term hydroxychloroquine therapy. JAMA ophthalmology, 132(12): 1453-1460.

6. Moschos, M. M., Nitoda, E., Chatziralli, I. P., Gatzioufas, Z., Koutsandrea, C., and Kitsos, G. (2015): Assessment of hydroxychloroquine maculopathy after cessation of treatment: an optical coherence tomography and multifocal electroretinography study. Drug design, development and therapy, 9: 2993.

7. Pasadhika, S., and Fishman, G. A. (2010): Effects of chronic exposure to hydroxychloroquine or chloroquine on inner retinal structures. Eye, 24(2): 340-346.

8. Shao, L., Xu, L., Chen, C. X., Yang, L. H., Du, K. F., Wang, S., ... and Wei, W. B. (2013): Reproducibility of subfoveal choroidal thickness measurements with enhanced depth imaging by spectral-domain optical coherence tomography. Investigative ophthalmology \& visual science, 54(1): 230233. 
ASSESSMENT OF EARLY RETINAL ANATOMICAL AND FUNCTIONAL...

9. Stepien, K. E., Han, D. P., Schell, J., Godara, P., Rha, J. and Carroll, J. (2009): Spectral-domain optical coherence tomography and adaptive optics may detect hydroxychloroquine retinal toxicity before symptomatic vision loss. Transactions of the American Ophthalmological Society, 107: 28-33.
10. Ulviye, Y., Betul, T., Nur, T. H., and Selda, C. (2013): Spectral domain optical coherence tomography for early detection of retinal alterations in patients using hydroxychloroquine. Indian journal of ophthalmology, 61(4): 168-171. 
تقييم التغير ات الوظيفية و التشريحية المبكرة التي تطر أ على كلى شبكية العين للمرضى المعالجون بعقار هيدروكسى كلوروكين

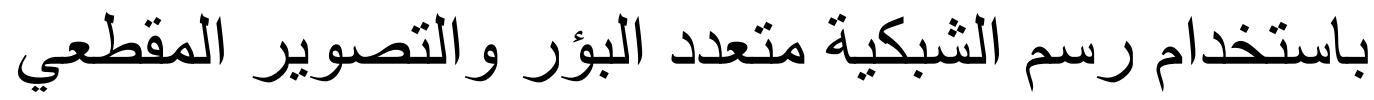

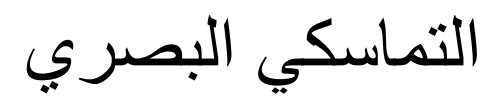

السيد مصطفى عليوه، مصطفى محمود مصطفى، احمد رجب عوض عمر

قسم طب وجراحة العيون، كلية الطب، جامعة الأزهر

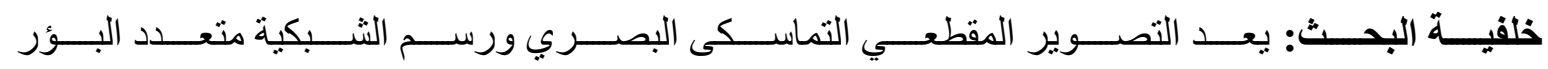

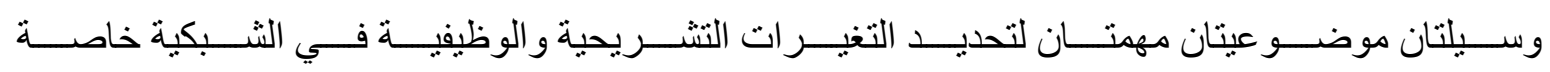
في المرحلة المبكرة من اعنالا الثبكية الذي يسببه عقار الهيدروكسي كلوروكين.

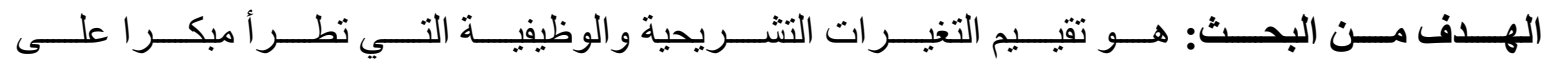

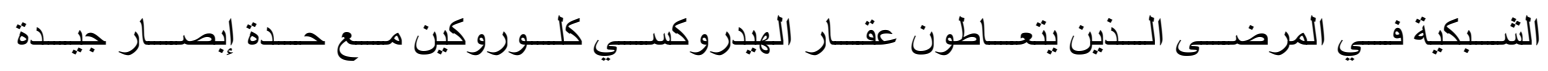

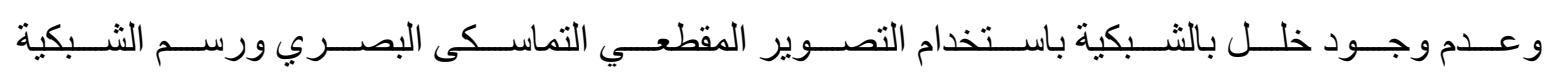
متعدد البؤر..

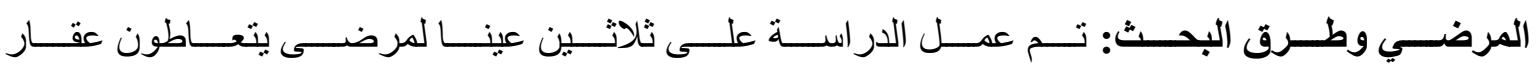

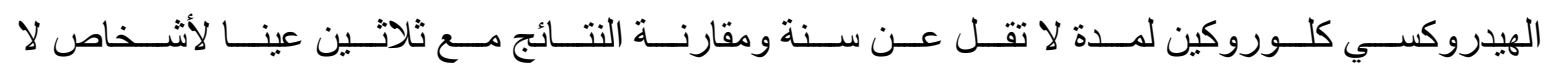

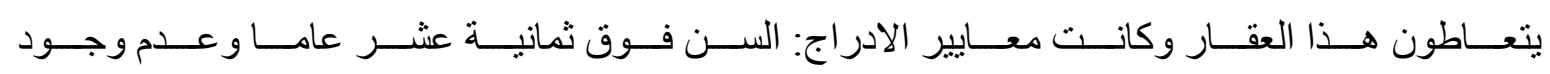

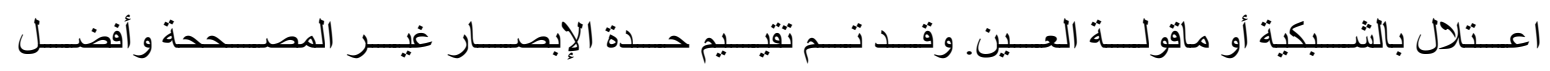

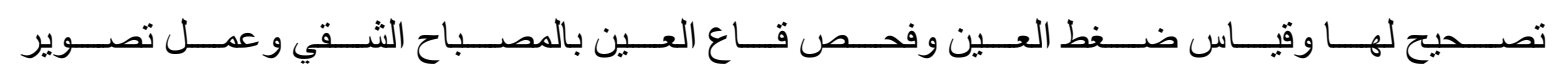
مقطعي للثبكية ورسم شبكية متعدد البؤري.

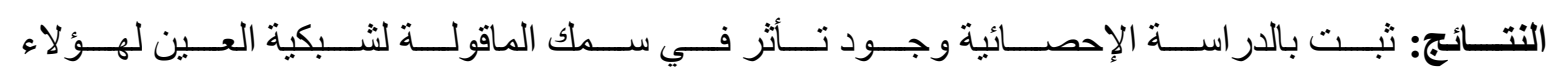

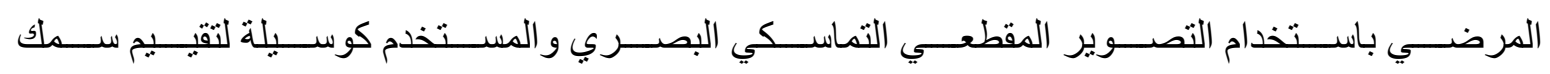

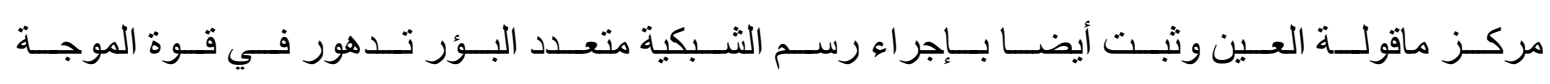

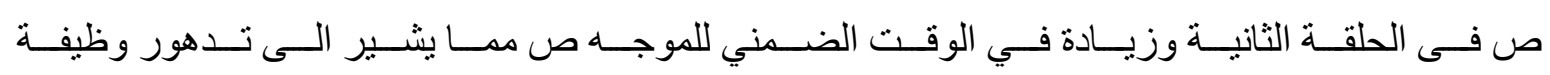

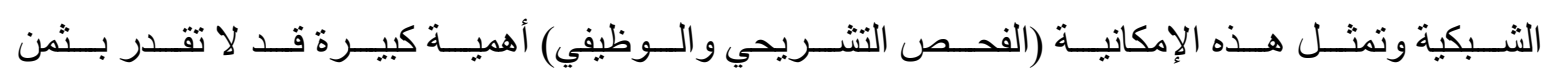
حيث يمكن إكتشاف تأثر الثبكية في مراحله المبكرة. 
ASSESSMENT OF EARLY RETINAL ANATOMICAL AND FUNCTIONAL...

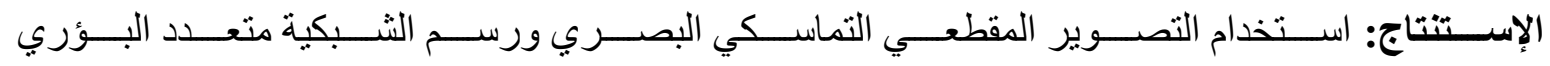
مهم كوسيلة للاكتشاف المبكر لسمية الهيدروكسي كلوروكين و أثناء المتابعات الدورية. 